\section{OMNIGRID: A general repertory grid design, administration, and analysis program}

\section{JOHN MITTERER and JACK ADAMS-WEBBER Brock University, St. Catharines, Ontario, Canada}

Kelly (1955) developed personal construct theory and an associated method of data collection and analysis, the repertory grid, which are both in widespread use in experimental and clinical settings. Since Kelly's original work, repertory grid technique has been elaborated in a variety of ways (Adams-Webber, 1987). Virtually all of the resulting techniques are amenable to automation. One approach, a computer program called OMNIGRID, is described in this report.

OMNIGRID is a public domain program that allows the user to choose from a wide selection of grid techniques (Mitterer \& Adams-Webber, 1988). It is primarily composed of three major subprograms: Configure, Collect, and Analyze. OMNIGRID was designed to be general, reliable, and valid. Generality has been achieved by placing the program in the public domain, allowing the selection of many of the currently available repertory grid options, and supplying full documentation to allow relatively simple modification and translation to other versions of BASIC. Reliability and validity have been achieved by including only testing and data analysis methods of established reliability and validity.

Input. The program requires two distinct types of input, that from the experimenter or clinician and that from the subject or client. The experimenter or clinician will use the Configure subprogram to design a repertory grid. Basically, the subprogram asks the user between 10 and 30 questions (from a set of 47) relevant to the design of a repertory grid. This subprogram, which is the heart of the OMNIGRID system, allows the design of a repertory grid, complete with a specification of constructs and elements, method of presentation, and desired data analyses. A manual and an on-line help file are available to guide the user through this portion of the program. Some of the options currently available include the following:

\section{Content:}

1. From 4 to 20 elements, including the "self" if desired, can be elicited or supplied (or both).

2. From 2 to 20 bipolar or unipolar constructs can be elicited or supplied (or both).

\section{Structure:}

1. The presentation of elements, element descriptions, constructs, and/or triads may be randomized across subjects or presented in a constant order for all subjects.

We would like to thank Steve Balz for his help in debugging OMNIGRID. Requests for the program should be addressed to Jack AdamsWebber, Department of Psychology, Brock University, St. Catharines, Ontario L2S 3A1, Canada.
2. The experimenter or clinician may elect to have subjects dichotomously classify (either constrained or unconstrained), rank order, or rate (using any desired scale) elements on constructs.

Analysis (all analyses are carried out on individual grids only):

1. The available analyses for dichotomous classification grids include matching scores, self-other differentiation, self-esteem, positivity bias, uncertainty $(H)$, salience, and interelement distances.

2. The available analyses for rank-order grids include Spearman's rho or Kendall's tau, average correlation between constructs, Kendall's concordance $(W)$, intensity, variance in common, and interelement distances.

3 . The available analyses for rating grids include Pearson's $r$, angular distances between constructs, extremity measures, variance in common, variability of intensity, interelement distances, observed-expected distances, and self-other distances.

Upon answering the configuration questions, the experimenter or clinician will be asked to supply elements or element descriptions, as well as constructs or even triads for construct elicitation, depending on what he/she has opted for. The input given to the Configure subprogram is stored in a "configuration file," which will subsequently determine how the program will administer and analyze the resulting repertory grid.

Upon supplying the Collect subprogram with the desired configuration file name, the subject or client will be asked to supply elements, constructs, and judgments about elements relative to constructs in the manner specified in the configuration file. After the subject or client has finished, the results will be saved in a "grid data file."

When the Analyze subprogram is supplied with a configuration file name and a grid data file name (the configuration file tells the analysis program what analyses to perform and the grid data file supplies the raw data for analysis), the requested analyses are done.

Output. The program offers two types of output, both of which can be sent to the screen or to a printer. One is a hard copy of the Configure file; the other is the output of the Analysis subprogam, which includes the list of elements, element descriptions, constructs, and/or triads, the raw grid data, and all requested analyses for that grid data file.

Program Language and Requirements. This version of OMNIGRID was written in APPLESOFT BASIC and will run on any APPLE II or APPLE II-compatible microcomputer with at least $64 \mathrm{~K}$ of memory and one disk drive. A printer for hard copy is desirable, although not necessary.

Availability. A diskette including the program and a file containing the manual (which can be read by APPLEWRITER II) is available from the authors for $\$ 15$. Please send postal money orders only. 


\section{REFERENCES}

Adams-Webber, J. R. (1987). Repertory grid technique. In R. Corsini (Ed.), Encyclopedia of psychology (pp. 973-974). New York: Wiley Interscience.

KELLY, G. A. (1955). The psychology of personal constructs. New York: Norton.
MitTERER, J., \& ADAMS-WEBbER, J. (1988). OMNIGRID: A program for construction, administration and analysis of repertory grids. In J. C. Mancuso \& M. L. G. Shaw (Eds). Cognition and personal structures: Computer access and analysis (pp. 89-103). New York: Praeger.

(Revision accepted for publication February 2, 1988.) 